\title{
Stiffness of lightly cemented sand under multiaxial loading
}

\author{
Marina Bellaver Corte ${ }^{1, *}$,Erdin Ibraim $^{2}$, Lucas Festugato $^{1}$, Andrea Diambra ${ }^{2}$, and Nilo Cesar Consoli ${ }^{1}$ \\ ${ }^{1}$ Federal University of Rio Grande do Sul, Civil Engineering Department, Av. Osvaldo Aranha, 99, 90035-190, Brazil \\ ${ }^{2}$ University of Bristol, Civil Engineering Department, BS8 1TR University Walk, United Kingdom
}

\begin{abstract}
This paper presents experimental triaxial tests conducted on two lightly cemented sand samples on the set-up conditions of a Hollow Cylinder Torsional Apparatus (HCTA). The laboratory study has been carried out on an angular to sub-angular silica sand reinforced with Portland cement of high early strength. The samples have identical porosity/volumetric cement content ratio, $\eta / \mathrm{C}_{\mathrm{iv}}$, values. The Young's modulus and shear modulus were measured by the application of a series of small unload-reload cycles at different investigation points along the triaxial stress path up to about $50 \%$ of the maximum deviatoric stress. At these investigation points, additional series of unload-reload cycles of higher amplitudes were also applied and the stiffness moduli assessed using local instrumentation. While the peak strength seems to be controlled by the density of the sand matrix, as extensive bond cementation damages occur at peak and pre-peak stages, the Young's modulus and shear modulus normalised by the void ratio function show the effect of the cementation ratio with higher values for the sample with higher cementation ratio.
\end{abstract}

\section{Introduction}

Soil properties commonly may not suit the construction project characteristics and requirements. An alternative is the addition of cement to the soil matrix. Previous studies of soil cement mixtures have shown that the behaviour of the material is complex, and it is affected by many factors, such as physical-chemical properties of the soil, the amount of cement and moisture of the mixture [1-4].

Saxena et al. [4] analysed a lightly cemented sand. The authors describe that in the Vincentown formation the highly cemented lenses represent the final stage of cementation process, while less cemented samples represent intermediate stages in incomplete cycles of cementation. Sharma and Fahey [5] showed that a relatively small amount of cement also able to increase the dynamic moduli and damping ratios of sands at low strain amplitudes. Arthur et al. [6] analysed the deformation characteristics of two cemented calcareous soils observing that by increasing the level of cementation the initial stiffness increases while the effect of confining pressure on the initial stiffness is progressively reduced.

The cement content and porosity of mixtures are two of the factors that must be consider in the dosage methodologies of cemented reinforced soils. Following a large number of soil element experiments under various cementation conditions and soil densities, Consoli et al. [3] found that, for a given soil treated with Portland cement, the unconfined compressive strength $\left(\mathrm{q}_{\mathrm{u}}\right)$ is controlled by an index representing the porosity/cement ratio $\left(\eta / C_{i v}\right)$ through a power relationship. Both the porosity $(\eta)$ and the volumetric cement content $\left(\mathrm{C}_{\mathrm{iv}}\right)$ are expressed as percentages of the total material volume.
This relationship was also shown to be valid for the expression of the tensile strength $\left(\mathrm{q}_{\mathrm{t}}\right)$ and on the assessment of durability of the treated mixtures [7-8].

This study investigates the stiffness and stiffness evolution of a lightly cemented reinforced sand under monotonic triaxial compression loading. Large loadunload-reload cycles are also applied before the samples' failure is reached. The tests are conducted in a Hollow Cylindrical Torsional Apparatus equipped with an advanced local strain measurement system. The determination of the cemented soil stiffness, Young's modulus and shear modulus, is done at different investigation points along the triaxial stress paths by the application of small unload-reload axial and torsional cycles, respectively. At each investigation point, additional series of axial and torsional cycles of higher amplitudes are also applied to probe the resistance of the cementation between the sand particles. While a large experimental programme considering the effect of the stress paths involving constant imposed rotation of principal stress axes is in progress, this paper presents only two tests, equivalent of triaxial tests on two samples of different densities reinforced by two different cement contents.

\section{Experimental set up}

\subsection{Hollow Cylinder Apparatus}

The Bristol HCTA was employed to investigate the evolution of the elastic properties of the cement reinforced sand $[9,10]$. The apparatus tests hollow cylinder samples

\footnotetext{
* Corresponding author: marinabellaver@gmail.com
} 
with $50 \mathrm{~mm}$ outer radius $\left(\mathrm{r}_{\mathrm{o}}\right), 30 \mathrm{~mm}$ inner radius $\left(\mathrm{r}_{\mathrm{i}}\right)$ and $200 \mathrm{~mm}$ height $(\mathrm{H})$ and, controls the axial load $(W)$, torque $(T)$ and internal $\left(P_{i}\right)$ and external $\left(P_{o}\right)$ pressures independently (Figure 1a).

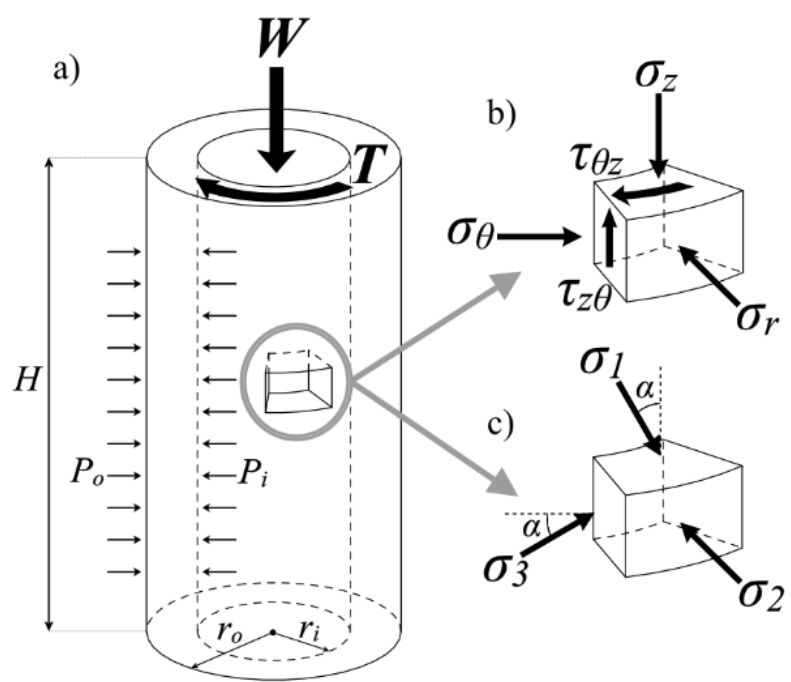

Fig. 1. (a) Imposed pressures and forces on the HCTA sample; (b) general stresses on soil element; (c) principal stress components on soil element.

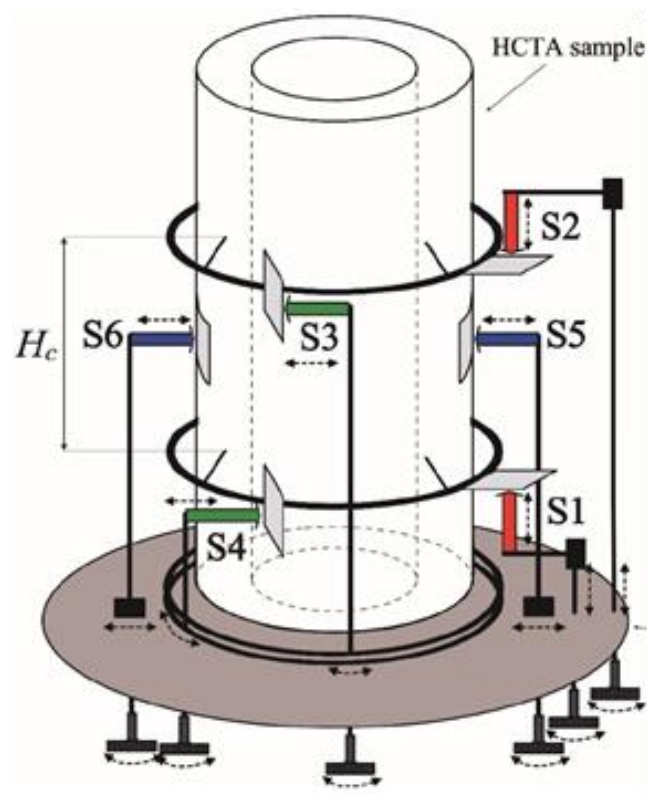

Fig. 2. Small strain measurement system of Bristol HCTA, after Ibraim et al. [9] and Mandolini et al. [11].

The application of these enables the control of all the stress components $\left(\sigma_{\mathrm{z}}, \sigma_{\mathrm{r}}, \sigma_{\theta}, \tau_{\theta \mathrm{z}}\right.$, Figure $\left.1 \mathrm{~b}\right)$ allowing the investigation of generalized stress paths which are characterised by four independent parameters: the mean principal effective stress $\left(\mathrm{p}^{\prime}\right)$, the deviatoric component of stress $\left(q=\sigma^{\prime}{ }^{\prime}-\sigma^{\prime}{ }_{\theta}\right)$, the intermediate principal stress parameter (b) and the angle between the major principal stress $\sigma_{1}$ and the vertical direction ( $\alpha$ in Figure 1c). For the tests presented in this paper, no control of the $b$ and $\alpha$ parameters were considered, the tests followed the classical triaxial stress path.

\subsection{Small Strain Measurement}

A general view of the local system of measurement of strains developed for the HCTA by [9] is shown in Figure 2. The measurement system consists of six non-contact displacement transducers (based on eddy current effect) with a measurement range of $2 \mathrm{~mm}$ and a resolution of $0.1 \mu \mathrm{m}$. The vertical and circumferential displacements are measured in the central part of the sample using two pairs of non-contact transducers (S1 and S2, S3 and S4, respectively) fixed on stainless steel rods. These transducers follow the movements of rectangular aluminium plate targets fixed on two parallel aluminium rings positioned in the central section of the sample at a distance $\mathrm{H}_{\mathrm{c}}$ of $100 \mathrm{~mm}$ (Figure 2). The rings are attached to the sample's external membrane by three flexible strips. The outer radial sample displacements are deduced by the average of the measurements given by two additional non-contact transducers (S5 and S6 in Figure 2) pointing at aluminium foil targets placed on the sample's side of the outer membrane - in direct contact with the sand. The current inner radius changes have been calculated from the volume changes of the inner cell (corrected for the membrane penetration effects) combined with the vertical sample variations.

In order to take advantage of the non-contact transducer's high resolution over a complete test and up to large strains, technical mechanical solutions able to allow the re-positioning, if necessary, of each pair of the non-contact transducers from outside the confining cell have been developed so the best accuracy for strains is maintained at various investigation points along the stress/strain paths $[9,11]$. The precisions with which the strains could be resolved are inferior to: $2 \times 10^{-6}(\mathrm{~m} / \mathrm{m})$ for axial strain, $\varepsilon_{\mathrm{z}}, 5 \times 10^{-6}(\mathrm{~m} / \mathrm{m})$ for radial strain, $\varepsilon_{r}, 10^{-7}$ $(\mathrm{m} / \mathrm{m})$ for circumferential strain, $\varepsilon \theta$, and $10^{-6}(\mathrm{~m} / \mathrm{m})$ for shear strain, $\gamma[9]$.

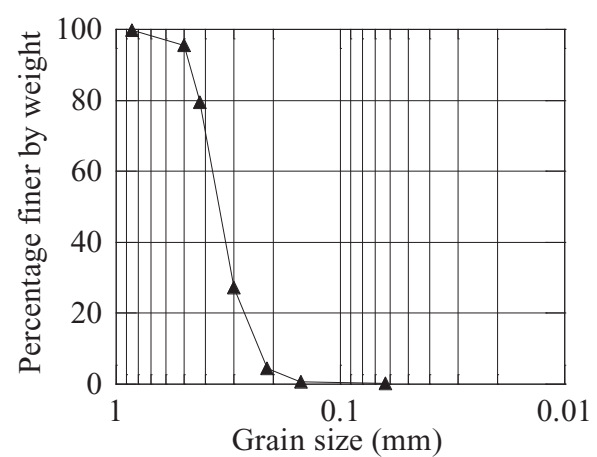

Fig. 3. Grain size distribution of Hostun RF (S28) sand.

\subsection{Materials}

Hostun RF (S28) sand tested in previous studies [12 - 14] was also used in this research. This sand has a high amount of siliceous $\left(\mathrm{SiO}_{2}>98 \%\right)$ and it has angular to sub-angular grain shape. The grain size distribution (Figure 3) shows an uniform graded sand with: mean grain size, $\mathrm{D}_{50}=0.32 \mathrm{~mm}$, coefficient of uniformity, $\mathrm{C}_{\mathrm{u}}=$ $\mathrm{D}_{60} / \mathrm{D}_{10}=1.70$, coefficient of gradation, $\mathrm{C}_{\mathrm{g}}=$ 
$\left(D_{30}\right) 2\left(D_{10} D_{60}\right)=1.1$, maximum and minimum void ratio, $\mathrm{e}_{\max }=1.00, \mathrm{e}_{\min }=0.62$, and specific gravity $\mathrm{G}_{\mathrm{s}}=2.65$.

The cementation agent used was a Portland cement of high initial strength (Type III, ASTM C 150-09; ASTM, 2009). As the cement has a fast gain of strength, 7 days curing time of cemented sand samples was adopted in this research.

\subsection{Specimen Preparation and test conditions}

Two mixtures of cement and sand were prepared, and hollow cylinder samples fabricated and tested. The composition and density of each sample have been chosen such way that both samples provide an identical $\eta / C_{i v}$ parameter of 47.24. While one of the samples $(\mathrm{C} 1.8 \mathrm{e} 0.707)$ has a lower amount of cement, $\mathrm{C}_{\mathrm{i}}=1.8 \%$ by dry mass of sand, its density is higher when both compared with the other sample (C2.3e 0.890), Table 1. The parameter e in Table 1 relates to the sample void ratio.

The required amount of sand and cement were first mixed until a uniform consistence was achieved. The water, $10 \%$ by mass of dry soil, was then added and the sand - cement composite mixed until a homogeneous material was obtained, at which point the mixture was divided in six portions corresponding to the amount of the successive soil layers used for the fabrication of the samples. Each sample layer was statically compacted with a steel curved tamper, inside of a curvilinear stainlesssteel mould. Between layers the top surface of the freshly made layer was scarified. After the preparation, the weight of mould + sample was measured, and the sample was kept inside the mould for curing, protected with plastic film and in a sealed plastic bag in environmentally controlled conditions of $22^{\circ} \mathrm{C}$ temperature and $60 \%$ humidity.

After five days of curing, the sample was removed from the mould, its dimensions measured and gently placed on the hollow cylinder apparatus. The internal instrumentation was then connected, the chamber cell pressure set in position and filled with water. After $\mathrm{CO}_{2}$ and de-aired water saturation, the samples were isotropically consolidated to a $\sigma_{\mathrm{z}}=\sigma_{\mathrm{r}}=\sigma_{\theta}=100 \mathrm{kPa}$ isotropic pressure and then tested by applying a deviator stress $q=\sigma_{z}-\sigma_{\theta}$. Throughout the test, the inner and outer cell pressures were maintained constant so that the $\sigma_{\mathrm{r}}=\sigma_{\theta}$ $=100 \mathrm{kPa}$.

\section{Results and Discussions}

Figure 4 presents the deviator stress and volumetric strain responses function of the axial strain for both $\mathrm{C} 2.3 \mathrm{e} 0.890$ and $\mathrm{C} 1.8 \mathrm{e} 0.707$ triaxial tests. In both tests, a peak strength is reached at about $0.06(\mathrm{~m} / \mathrm{m})$ strain level, at which point the tests were stopped as stress control conditions were adopted. The denser sample having a low amount of cement content shows higher mobilised strength compared with low density and higher cement content sample. Both samples show compressive volumetric response in the early stages of the tests, with higher contraction for the less dense sample. The initial vertical stress-vertical strain curves over a very low range of strain are linear up to about $2 \times 10^{-5} \mathrm{~m} / \mathrm{m}$ for both $\mathrm{C} 2.3 \mathrm{e} 0.890$ and $\mathrm{C} 1.8 \mathrm{e} 0.707$ tests and the initial Young's moduli measured with the local instrumentation gives almost identical values 242MPa (Figure 5) and 240MPa (Figure 6), respectively.

The initial Young's modulus seems to be controlled by both the cementation ratio and sample density and their combination having the same $\eta / \mathrm{C}_{\mathrm{iv}}$ value appears to provide similar initial stiffness. Removing the effect of the density through the application of a void ratio function [15]:

$$
F(e)=\frac{(3.01-e)^{2}}{1+e}
$$

would clearly show the effect of the higher cementation ratio providing a higher normalised stiffness. However, as the loading advances, the behaviour becomes highly nonlinear and the response in large strains is becoming more reminiscent of a granular soil, with likely occurrence of cemented bond breakages at peak and pre-peak stages. The denser sample shows higher peak strength than the less dense one and the response at peak failure is more controlled by sand matrix than cementation. Analysis of the state of the sample at the end of the test showed a fine granular structure with an almost complete damage of the cementation. In both tests, at about $50 \%$ of the maximum deviatoric stress, one large unload-reload cycle was also applied, as shown in Figure 4c, before loading the tests monotonically towards the failure. During these large load-unload-reload cycles, at different investigation points, noted by roman letters in the figure, and after creep stages of about half-an-hour, unload-reload cycles of relatively low amplitudes were applied independently in both axial and torsional directions. During the application of the torsional cycles, all the vertical, radial and circumferential stresses were maintained constant with the vertical stress corresponding to the current level attained at the investigation point. At the start of the tests, point (I), no cycles were applied and only the Young's modulus was measured from the slope of the linear vertical stress-strain curve as discussed above. At all the other investigation points, a number of 10 successive cycles were applied for each $\Delta \sigma_{z}$ half-cycle amplitude of $\pm 2.5 \mathrm{kPa}, \pm 5 \mathrm{kPa}$, and $\pm 10 \mathrm{kPa}$, followed by 10 cycles for each $\Delta \tau_{\mathrm{z} \theta}$ half-cycle amplitude of $\pm 2.5 \mathrm{kPa}, \pm 5 \mathrm{kPa}$, and $\pm 10 \mathrm{kPa}$. The frequency of the small cycles was $0.1 \mathrm{~Hz}$ and the data acquisition was done at a frequency of 3 Samples/s. The variation of the deviator stress with up to and including the succession of cycles for the investigation point (II) is shown in Figure 7.

Table 1. Sample characteristics.

\begin{tabular}{|c|c|c|c|c|}
\hline Test Name & $\boldsymbol{e}$ & $\begin{array}{c}\mathbf{C i} \\
\mathbf{( \% )}\end{array}$ & $\boldsymbol{\eta} / \mathbf{C}_{\mathbf{i v}}$ & Curing Time \\
\hline $\mathrm{C} 2.3 \mathrm{e} 0.890$ & 0.890 & 2.3 & & \\
\cline { 1 - 3 } $\mathrm{C} 1.8 \mathrm{e} 0.707$ & 0.707 & 1.8 & 47.24 & 7 days \\
\hline
\end{tabular}



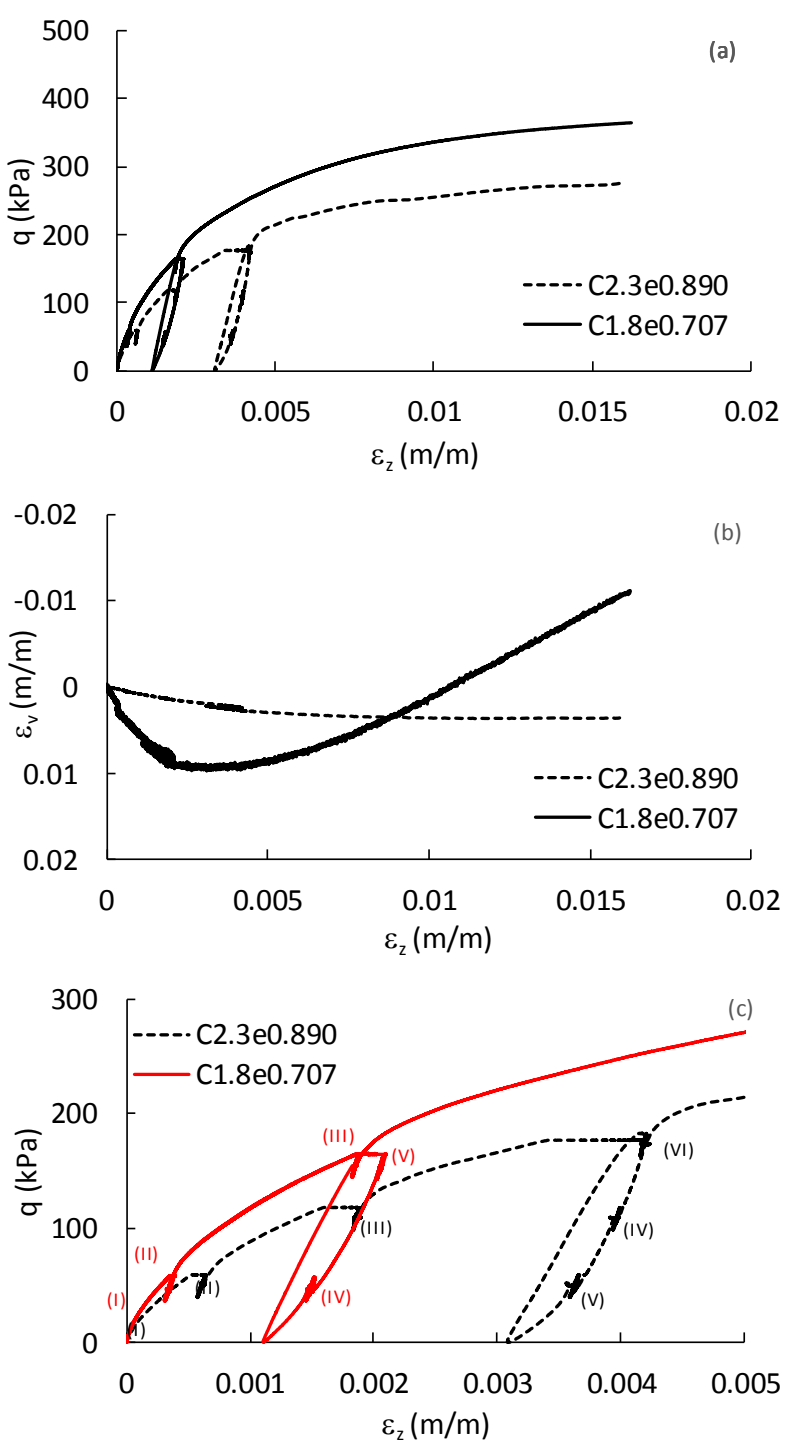

Fig. 4. Tests $\mathrm{C} 2.3 \mathrm{e} 0.890$ and $\mathrm{C} 1.8 \mathrm{e} 0.707$ : (a) Deviatoric stress versus deviatoric strain; (b) Volumetric strain versus deviatoric strain component; (c) Load-unload and reload loop with investigation point of the small strain stiffness.

Typical unload-reload cycles applied in axial and torsional directions at the investigation point (II) for the tests $\mathrm{C} 2.3 \mathrm{e} 0.890$ are shown as an example in the Figure 8 and Figure 9, respectively. The Young's modulus, $\mathrm{E}_{\mathrm{z}}=\Delta \sigma_{\mathrm{z}} / \Delta \varepsilon_{\mathrm{z}}$, and shear modulus, $\mathrm{G}_{\mathrm{z} \theta}=\Delta \tau_{\mathrm{z} \theta} / \Delta \tau_{\mathrm{z} \theta}$, were calculated from the slopes of the stress-strain curves, as shown in the figures. The double amplitude of the cyclic axial strain response reaches $2 \times 10^{-5}(\mathrm{~m} / \mathrm{m})$ for $\pm 2.5 \mathrm{kPa}$ cyclic axial stress amplitude, $3.6 \times 10^{-5}$ for $\pm 5.0 \mathrm{kPa}$ and approximately $7 \times 10^{-5}$ for $\pm 10 \mathrm{kPa}$ cyclic axial stress amplitude. For one amplitude, the superposition of the stress-strain relations for the successive applied cycles is identical with no or very limited (for the highest cyclic loading amplitude) hysteresis, and linear fitting for Young's modulus evaluation through all the data can be applied. The values of the Young's modulus are identical for the first two cyclic amplitudes of $\pm 2.5 \mathrm{kPa}$ and \pm 5.0 $\mathrm{kPa}$. A very slight reduction of the Young's modulus is recorded for the highest cyclic amplitude of $\pm 10 \mathrm{kPa}$ as a consequence of some very limited particle cemented bond breakages that may be likely to occur. Similar observations can be made on the shear stress-shear strain probing shown in the Figures $9 \mathrm{a}, \mathrm{b}$ and $\mathrm{c}$. The double amplitude of the cyclic shear strain response reaches $3.8 \times 10^{-5}, 7.1 \times 10^{-5}$ and $14.8 \times 10^{-5}$ for $\pm 2.5 \mathrm{kPa}, \pm 5.0 \mathrm{kPa}$ and $\pm 10.0 \mathrm{kPa}$ cyclic shear stress amplitudes, respectively.

The elastic Young's modulus was shown to be dependent on the normal stress in the direction of measurement following a power law $[16,17]$. The density of soil also affects the stiffness and its influence is normally taken into account by the use of a void ratio function, $\mathrm{F}(\mathrm{e})$ in the form given by relation (1) [15]. It is also recognised that the shear modulus is mainly dependent on the two normal stresses acting on the plane of shear and independent of the stress acting normal [18].

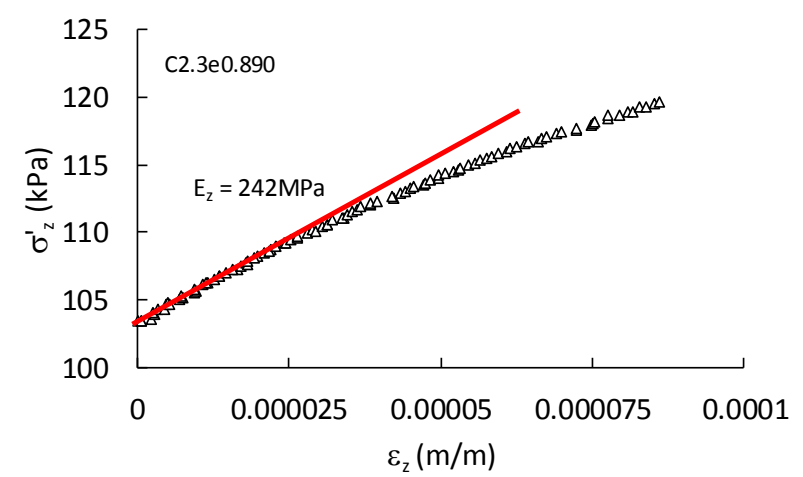

Fig. 5. Test $\mathrm{C} 2.3 \mathrm{e} 0.890$ : initial response and Young's Modulus estimation.

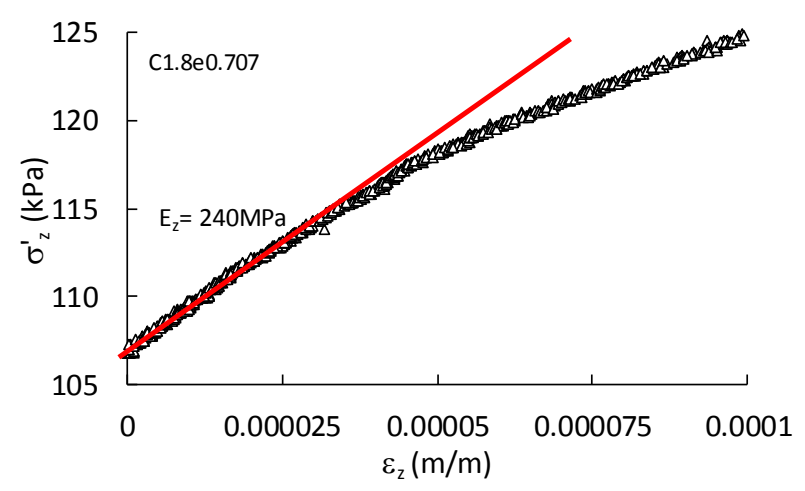

Fig. 6. Test $\mathrm{C} 1.8 \mathrm{e} 0.707$ : initial response and Young's Modulus estimation.

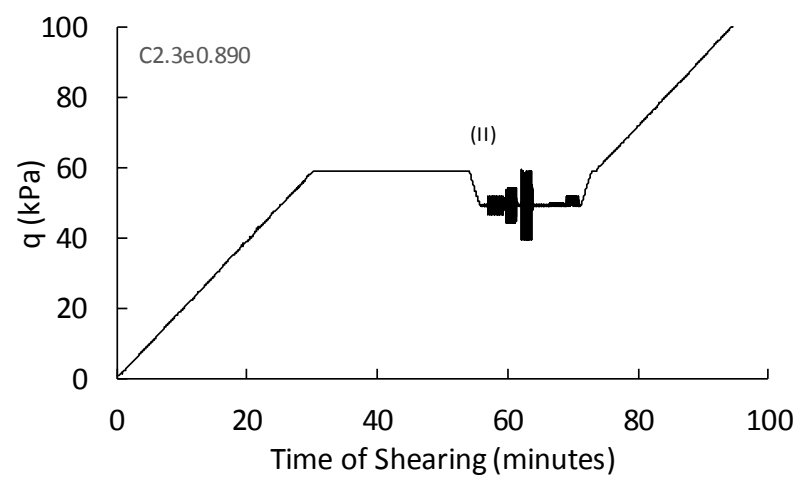

Fig. 7. Test $\mathrm{C} 2.3 \mathrm{e} 0.890$ : initial loading, creep, small cycles and loading function of time. 

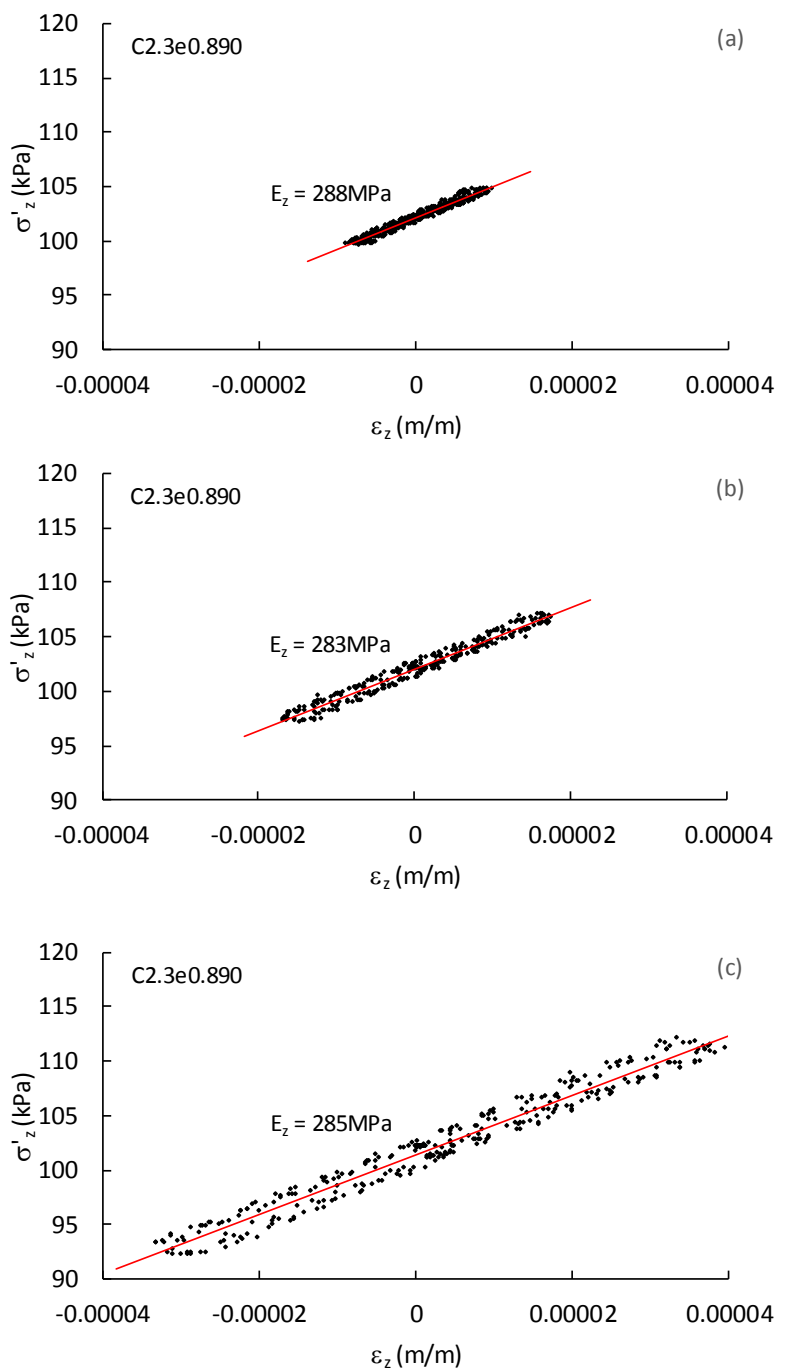

Fig. 8. Test C2.3e0.890: examples of small vertical strain cycles, investigation point (II), and Young's modulus estimation.

Figure 10 shows the stress dependency of the Young's modulus (deduced for the smallest applied cyclic amplitude of $\pm 2.5 \mathrm{kPa}$ ) for both $\mathrm{C} 1.8 \mathrm{e} 0.707$ and $\mathrm{C} 2.3 \mathrm{e} 0.890$ tests. The effect of the void ratio variation was removed by normalising the stiffness values by the void ratio function (1). For both tests, the Young's modulus follows a power law as a function of $\sigma_{\mathrm{z}}$ with constant power values of 0.48 for $\mathrm{C} 2.3 \mathrm{e} 0.890$ and 0.53 for $\mathrm{C} 1.8 \mathrm{e} 0.707$. These power exponents are within the expected values for sand and close to those obtained by [9]. In the generation of the equations presented in the Figure 10, a reference pressure of $1 \mathrm{kPa}$ was also used. However, the Young 's modulus of the sample having a higher cement content (and lower density) is higher than for the sample with lower cement content (and higher density). For the range of vertical stresses at which the stiffness was assessed, these results seem to imply that the cementation, is still able to offer enough reinforcement, controlling the stiffness of the mixture. . The reduction of stiffness for lower cementation ratio, could also be the result of small bond degradations induced by loading and small amplitude cycles as also observed by [5].
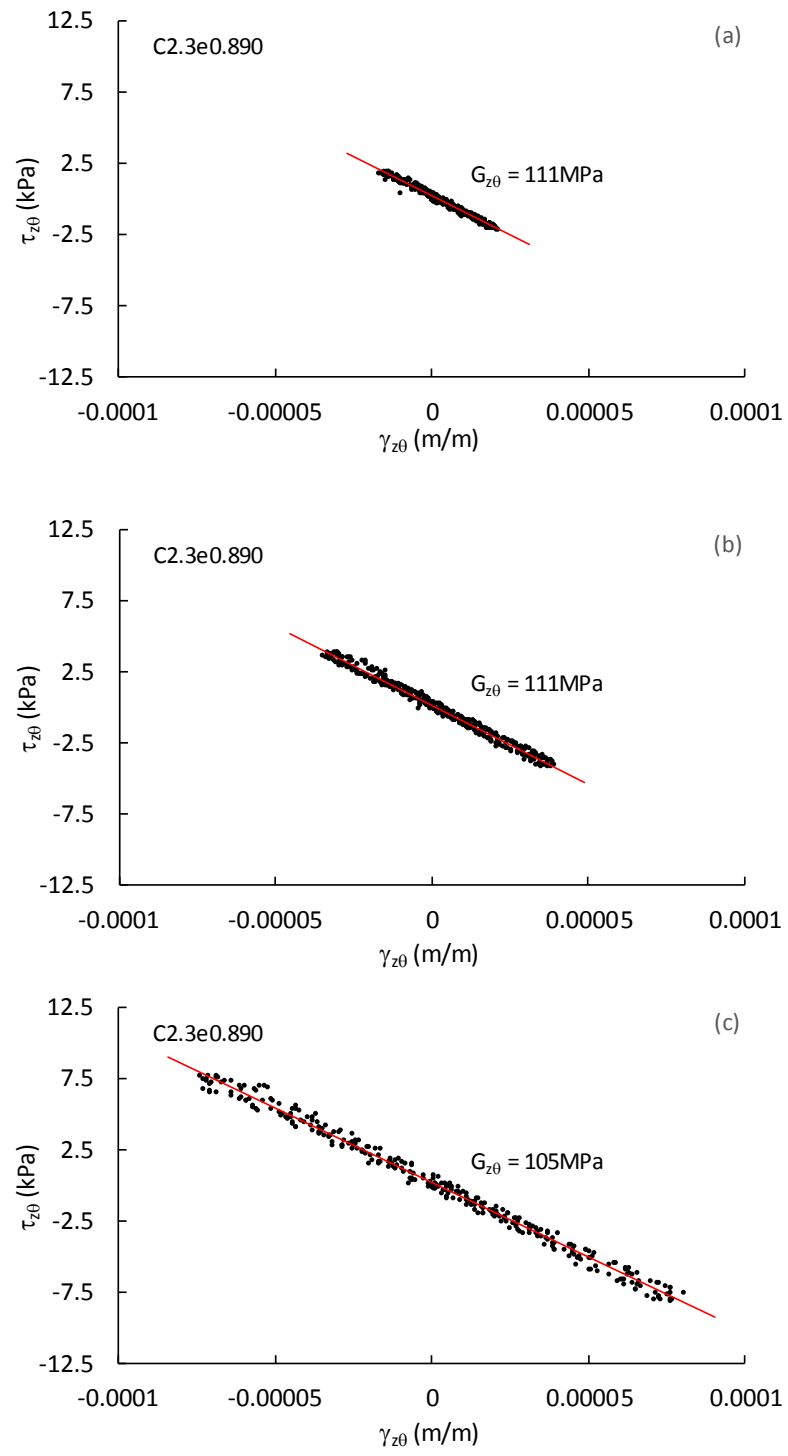

Fig. 9. Test $\mathrm{C} 2.3 \mathrm{e} 0.890$ : examples of small torsional shear strain cycles, investigation point (II), and shear modulus estimation.

Figure 11 presents the stress dependency of the shear modulus for both tests, with the shear stiffness measured at the investigation points for $\Delta \tau_{\mathrm{z} \theta}$ cycle of $\pm 2.5 \mathrm{kPa}$. The same normalisation of the stiffness values with the void ratio function (1) was applied. Again, the shear stiffness of the tests $\mathrm{C} 2.3 \mathrm{e} 0.890$ is higher than the shear stiffness of the test with lower cement content, $\mathrm{C} 1.8 \mathrm{e} 0.707$. For the former test, the stress dependency of $\mathrm{G}_{\mathrm{z} \theta} / \mathrm{F}(\mathrm{e})$ follows a function $\left(\sigma^{\prime}{ }_{z} \sigma^{\prime} \theta\right)^{0.5 n}$ with $n=1.10$, again close to values of most of the sand soils. However, for reasons which we have not been able to identify, the normalised shear stiffness measured at the investigation points (III) and (V) of the test $\mathrm{C} 1.8 \mathrm{e} 0.707$ showed anomalous data with similar values as measured at the investigation points (II) and (IV) and no effect of the stress level. 


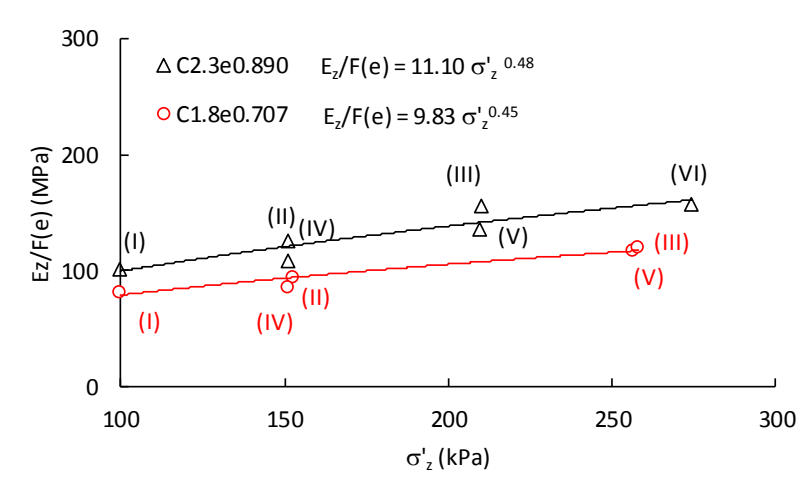

Fig. 10. Normalised Young's modulus $E_{z} / F(e)$ with the stress level for both tests.

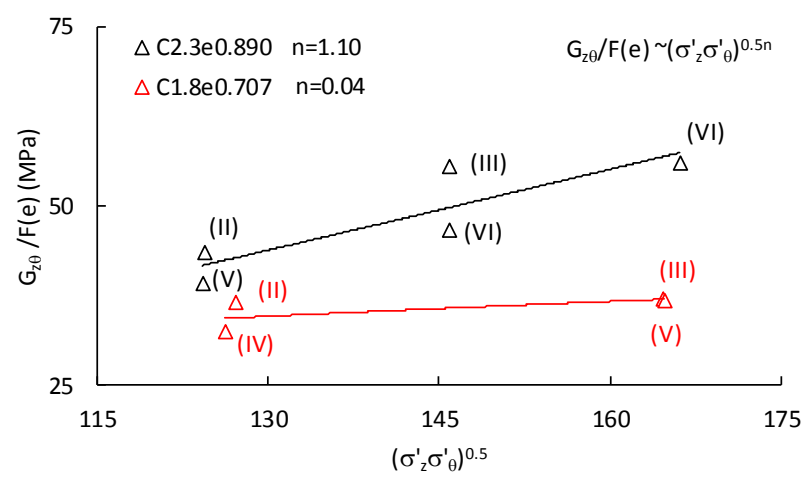

Fig. 11. Normalised shear modulus $G_{z \theta} / F(e)$ with the stress level for both tests.

\section{Conclusions}

This paper presents two experimental triaxial tests conducted on lightly cemented samples on the set-up conditions of a Hollow Cylinder Torsional Apparatus (HCTA). The general behaviour in triaxial test conditions was explored as well as the small strain stiffness of the cemented soil. Young's modulus and shear modulus were measured by the application of a series of small unload reload cycles at different investigation points during the triaxial tests. Non-contact high-resolution displacement transducers where used to measure the quasi-elastic properties of the material and their dependency on the stress state, density and cement content. For two lightly cemented samples with similar porosity/volumetric cement content ratio, $\eta / C_{i v}$, values, the peak strength seems to be controlled by the density of the sand matrix as extensive bond cementation damages occur at peak and pre-peak stages. The normalised Young's modulus and shear modulus, by the void ratio function, determined at different investigation points up to about $50 \%$ of the maximum deviatoric stress show the effect of the cementation ratio with higher values for the sample with higher cementation ratio. Limited bond degradation appears to be occurring at these stress level conditions. A large experimental programme considering the effect of the stress paths involving constant imposed rotation of principal stress axes is in progress and the results will be reported in a future communication.
The first author would like to express her gratitude to the Brazilian Research Council (CNPq) for the financial support.

\section{References}

1. R. K. Moore, T. W. Kennedy, W. R. Hudson, Highway Res. Rec. 315, 64-80 (1970)

2. G. W. Clough, N. Sitar, R. C. Bachus, N. S. Rad, J. Geotech. Geoenv. Eng. 107, 6, 799-817 (1981)

3. N. C. Consoli, D. Foppa, L. Festugato, K. S. Heineck. J. Geotech. Geoenviron. Eng. 133, 2, 197- 205 (2007)

4. S. K. Saxena, R. M. Lastrico. J. Geotech. Geoenv. Eng. 104. 12 (1978)

5. S. S. Sharma, M. Fahey. Can Geotech. 41, 4439-1151 (5114)

6. J. R. F Arthur, K. S. Chua, T Dunstan, J. I, Rodriguez del C. J. Geotech. Geoenv. Eng. 106, 4 (1980)

7. N. C. Consoli, R. R. Moraes, L. Festugato. J. Mater. Civ. Eng. 25, 1567-1573 (2013)

8. N. C. Consoli, A. P. da Silva, H. P. Nierwinsky, J. Sosnosky, Can. Geotech. 55, 486-494 (2018)

9. E. Ibraim, P. Christiaens, M. Pope. GEJ of the SEAGS \& AGSSEA, 42, 4 (2011)

10. A. Mandolini, A. Diambra, E. Ibraim. Géotechnique, 69(3), 203-216, (2019)

11. A. Mandolini, A. Diambra, E. Ibraim. ISSMGE, 447450 (2017)

12. T. Doanh, E. Ibraim, 2000, Géotechnique, 50(4), 377 $-392,(2000)$

13. A. Diambra, E. Ibraim, A. Russell, D. Muir Wood. Soils and Found., vol. 51, no. 4, 625 - 636, (2011)

14. A. Diambra, E. Ibraim, Géotechnique, 65(4), 296308 (2015)

15. B.O. Hardin, F.E. Richart J. of Soil Mechanics \& Found Division, 89(SM1) 33-65 (1963)

16. B. O. Hardin, G. E. Blandford, J. Geotech. Eng., 115 (6), 788-805. (1989)

17. F. Tatsuoka, G. Modoni, G. L. Jiang, L. Q. Anh Dan, A. Flora, M. Matsushita, J. Koseki. Keynote Lecture, Proceedings, Workshop on Modelling and Advanced Testing for Unbound Granular Materials, Eds., Balkema, 7-61(1999)

18. S. K. Roesler, J. Geot Eng., ASCE 105(GT7), 871880 (1979) 